\title{
Enantioseparation using amylose esters as chiral stationary phases for high-performance liquid chromatography
}

\author{
Yuri Sugiura $^{1}$, Chiyo Yamamoto $^{2}$, Tomoyuki Ikai $^{3}$, Masami Kamigaito ${ }^{1}$ and Yoshio Okamoto ${ }^{3,4}$ \\ Novel amylose ester derivatives were synthesized and their chiral recognition abilities as chiral stationary phases for high- \\ performance liquid chromatography were evaluated. Compared with amylose benzoate derivatives, cinnamate derivatives showed \\ a higher chiral recognition ability and some racemates could be efficiently resolved. The recognition abilities of these derivatives \\ varied significantly depending on the types and positions of substituents introduced into the phenyl group. Among the prepared \\ derivatives, the nonsubstituted cinnamate derivative showed a relatively high chiral recognition, and interestingly, its ability was \\ influenced by the preparation conditions of packing materials using silica gel as a support.
}

Polymer Journal (2010) 42, 31-36; doi:10.1038/pj.2009.300

Keywords: cellulose; chiral separation; cinnamate; HPLC; polysaccharide; resolution

\section{INTRODUCTION}

Over the past 40 years, efficient chiral stationary phases (CSPs) for high-performance liquid chromatography (HPLC) have been developed to improve their recognition ability, loading capacity and applicability. ${ }^{1-9}$ Among more than 100 commercially available CSPs, polysaccharide-based CSPs, which can be prepared from natural chiral sources such as cellulose and amylose, have been recognized as the most powerful and practical for resolving a wide range of racemates. ${ }^{10-16}$

Since Hesse and Hagel ${ }^{17,18}$ developed the practical CSP on the basis of microcrystalline cellulose triacetate CTA-I in 1973, various kinds of cellulose esters, such as benzoates and cinnamate, have been prepared to evaluate their recognition abilities as CSPs for HPLC. ${ }^{19-21}$ Among them, cellulose benzoates show high recognition abilities when they are coated on silica gel. The recognition ability of cellulose benzoates depends to a large extent on the nature of the substituents on the phenyl groups. ${ }^{21}$ The most likely explanation for this observation is that the electron density of the carbonyl groups of cellulose benzoates is affected by the inductive effect of substituents on the phenyl groups, which may influence the hydrogen bonding formation or dipoledipole interaction on this group.

On the other hand, amylose esters have not yet been studied in detail, probably because they show much lower recognition abilities than cellulose esters. ${ }^{22}$ This may be because of the lower conformational stability of amylose derivatives, which causes the formation of many conformational isomers. Therefore, proper structural modification is necessary to prepare practical CSPs based on the amylose esters.
In this study, we prepared various kinds of novel amylose esters and evaluated their abilities as CSPs for HPLC in order to expand the possibility of chiral separation using polysaccharide derivatives.

\section{EXPERIMENTAL PROCEDURE}

Materials

Amylose (DP 300) was kindly supplied by Daicel Chemical Industries (Tokyo, Japan). p-Toluoyl chloride, cinnamoyl chloride, 3-fluorocinnamic acid, 2 -acetylfuran and 3-aminopropyltriethoxysilane were purchased from Tokyo Kasei (Tokyo, Japan). 2-Naphthoic acid, dehydrated pyridine and dehydrated toluene were obtained from Kanto (Tokyo, Japan). 4-Biphenylcarboxylic acid, 4-tert-butylbenzoyl chloride, 4-methylcinnamic acid and $\alpha$-methylcinnamic acid were purchased from ACROS (Geel, Belgium). Hydrocinnamoyl chloride, trans-2-phenyl-1-cyclopropanecarbonyl chloride, 4-chlorocinnamic acid, 4fluorocinnamic acid and 2-fluorocinnamic acid were obtained from Aldrich (Milwaukee, WI, USA). Thionyl chloride was purchased from Wako (Osaka, Japan). Macroporous spherical silica gel (Daiso gel SP-1000) with a mean particle size of $7 \mu \mathrm{m}$ and a mean pore diameter of $100 \mathrm{~nm}$ was kindly supplied by Daiso Chemical (Tokyo, Japan). The racemates were commercially available or were prepared by the usual methods. ${ }^{23}$

Synthesis of amylose esters

2-Naphthoic acid chloride, 4-biphenylcarboxylic acid chloride, 4-methylcinnamoyl chloride, 4-chlorocinnamoyl chloride, fluorocinnamoyl chlorides and $\alpha$-methylcinnamoyl chloride were prepared from 2-naphthoic acid, 4-biphenylcarboxylic acid, 4-methylcinnamic acid, 4-chlorocinnamic acid, fluorocinnamic acids and $\alpha$-methylcinnamic acid, respectively, through a reaction with 


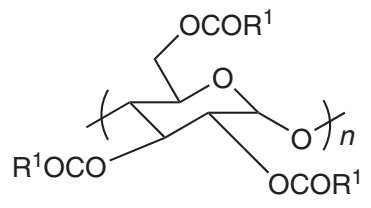

Amylose esters

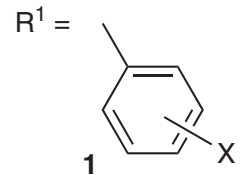

2<smiles>Cc1ccc2ccccc2c1</smiles>

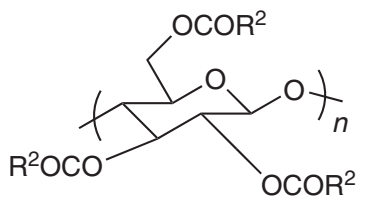

Cellulose ester

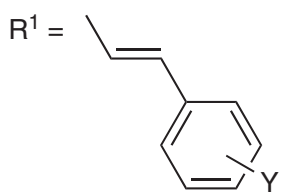

3<smiles>CC(C)=Cc1ccccc1</smiles>

4

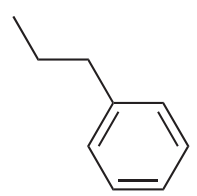

5

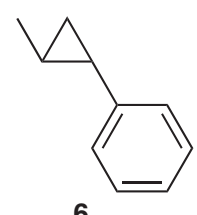

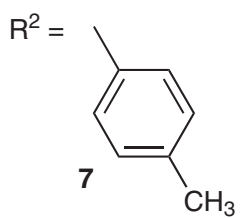

$$
X=\left\{\begin{array}{ll}
\text { a: } 4-\mathrm{CH}_{3} \\
\text { b: } 4-C\left(\mathrm{CH}_{3}\right)_{3} \\
\text { c: } 4-\mathrm{Ph}
\end{array} \quad Y= \begin{cases}\text { a: } \mathrm{H} & \text { d: } 4-\mathrm{F} \\
\text { b: } 4-\mathrm{CH}_{3} & \text { e: } 3-\mathrm{F} \\
\text { c: } 4-\mathrm{Cl} & \text { f: } 2-\mathrm{F}\end{cases}\right.
$$

Figure 1 Structures of ester derivatives of amylose (1-6) and cellulose (7).

Table 1 Elemental analysis of amylose esters

\begin{tabular}{lccccc}
\hline & \multicolumn{3}{c}{ Found (\%) } & & \multicolumn{2}{c}{ Calculated (\%) } \\
\cline { 2 - 3 } \cline { 5 - 6 } & C & & & C & $H$ \\
\hline 1a & 69.80 & 5.21 & 69.76 & 5.46 \\
1b & 72.67 & 7.06 & & 72.87 & 7.21 \\
1c & 75.99 & 4.81 & 76.91 & 4.88 \\
2 & 74.82 & 4.50 & & 74.99 & 4.52 \\
3a & 71.96 & 5.15 & & 71.73 & 5.11 \\
3b & 72.85 & 5.84 & & 72.71 & 5.76 \\
3c & 61.06 & 3.41 & 60.43 & 3.84 \\
3d & 65.25 & 4.06 & 65.35 & 4.15 \\
3e & 65.41 & 3.91 & 65.35 & 4.15 \\
3f & 65.36 & 4.07 & 65.35 & 4.15 \\
4 & 72.82 & 5.87 & 72.71 & 5.76 \\
$\mathbf{5}$ & 71.02 & 5.98 & 70.95 & 6.13 \\
$\mathbf{6}$ & 72.56 & 5.65 & 72.71 & 5.76 \\
\hline
\end{tabular}

Based on a repeated glucose unit.

thionyl chloride at $80^{\circ} \mathrm{C}$. Amylose esters (1-6) (Figure 1) were synthesized by the reaction of amylose with an excess amount of the corresponding acid chloride at $80^{\circ} \mathrm{C}$ in pyridine. The derivatives were isolated as methanolinsoluble solids. Elemental analysis (Table 1) and ${ }^{1} \mathrm{H}$ NMR spectra for 1-6 showed that the hydroxy groups of amylose were almost quantitatively converted into ester moieties. 1a: IR $(\mathrm{KBr}): 1724\left(v_{\mathrm{C}=\mathrm{O}}\right) ;{ }^{1} \mathrm{H}$ NMR $\left(\mathrm{CDCl}_{3}\right)$ : $\delta 2.1-2.4\left(\mathrm{CH}_{3}(9 \mathrm{H})\right), 4.13,4.25,4.38,4.59,4.98,5.50,5.73$ (br, glucose protons, $7 \mathrm{H}), 6.82,6.85,7.16,7.36,7.48,7.94$ (aromatic, $12 \mathrm{H}$ ). 1b: IR (KBr): 1735 $\left(v_{\mathrm{C}=\mathrm{O}}\right) ;{ }^{1} \mathrm{H} \mathrm{NMR}\left(\mathrm{CDCl}_{3}\right): \delta 1.1-1.5\left(\mathrm{CH}_{3}(27 \mathrm{H})\right), 4.2-5.8$ (br, glucose protons, $7 \mathrm{H})$, 6.9-8.1 (aromatic, $12 \mathrm{H})$. 1c: IR $(\mathrm{KBr}): 1723\left(v_{\mathrm{C}=\mathrm{O}}\right) ;{ }^{1} \mathrm{H}$ NMR $\left(\mathrm{CDCl}_{3}\right)$ : 84.3-6.0 (br, glucose protons, 7H), 7.0-8.0 (aromatic, 27H). 2: IR (KBr): 1724 $\left(v_{\mathrm{C}=\mathrm{O}}\right) ;{ }^{1} \mathrm{H}$ NMR $\left(\mathrm{CDCl}_{3}\right): \delta 4.4-6.2$ (br, glucose protons, $\left.7 \mathrm{H}\right), 6.9-8.5$ (aromatic, 21H). 3a: IR ( $\mathrm{KBr}): 1718\left(v_{\mathrm{C}=\mathrm{O}}\right) ;{ }^{1} \mathrm{H}$ NMR $\left(\mathrm{CDCl}_{3}\right)$ : $\delta 4.1-5.9$ (br, glucose protons, 7H), 6.0-7.9 (aromatic and $-\mathrm{CH}=\mathrm{CH}-$, 21H). 3b: IR $(\mathrm{KBr}): 1719\left(v_{\mathrm{C}=\mathrm{O}}\right) ;{ }^{1} \mathrm{H}$ NMR (pyridine- $\left.d_{5}\right): \delta 1.9-2.4\left(\mathrm{CH}_{3}(9 \mathrm{H})\right), 4.6-6.5(\mathrm{br}$, glucose protons, $7 \mathrm{H}$ ), $6.5-8.2$ (aromatic, $-\mathrm{CH}=\mathrm{CH}-, 18 \mathrm{H}$ ). 3c: $\mathrm{IR}(\mathrm{KBr}): 1720$
$\left(v_{\mathrm{C}=\mathrm{O}}\right) ;{ }^{1} \mathrm{H}$ NMR (pyridine- $\left.d_{5}\right)$ : $\delta 4.6-6.5$ (br, glucose protons, $7 \mathrm{H}$ ), 6.4-8.1 (aromatic, $-\mathrm{CH}=\mathrm{CH}-, 18 \mathrm{H})$. 3d: IR $(\mathrm{KBr}): 1722\left(v_{\mathrm{C}=\mathrm{O}}\right) ;{ }^{1} \mathrm{H}$ NMR $\left(\mathrm{CDCl}_{3}\right)$ : 84.0-5.9 (br, glucose protons, 7H), 5.9-7.9 (aromatic, $-\mathrm{CH}=\mathrm{CH}-, 18 \mathrm{H}) .3 \mathrm{e}: \mathrm{IR}$ $(\mathrm{KBr}): 1722\left(v_{\mathrm{C}=\mathrm{O}}\right) ;{ }^{1} \mathrm{H}$ NMR $\left(\mathrm{CDCl}_{3}\right): \delta 4.0-5.9$ (br, glucose protons, $\left.7 \mathrm{H}\right)$, 5.9-7.9 (aromatic, $-\mathrm{CH}=\mathrm{CH}-, 18 \mathrm{H})$. 3f: IR $(\mathrm{KBr}): 1724\left(v_{\mathrm{C}=\mathrm{O}}\right) ;{ }^{1} \mathrm{H}$ NMR $\left(\mathrm{CDCl}_{3}\right)$ : $83.9-5.9$ (br, glucose protons, $\left.7 \mathrm{H}\right), 5.9-8.0$ (aromatic, $-\mathrm{CH}=\mathrm{CH}-$, 18H). 4: IR ( $\mathrm{KBr}): 1716\left(v_{\mathrm{C}=\mathrm{O}}\right) ;{ }^{1} \mathrm{H}$ NMR (pyridine- $\left.d_{5}\right): \delta 1.6-2.2\left(\mathrm{CH}_{3}(9 \mathrm{H})\right)$, 3.9-5.9 (br, glucose protons, 7H), 6.8-7.8 (aromatic, $\mathrm{C}=\mathrm{CH}-$, 18H). 5: IR $(\mathrm{KBr}): 1747\left(v_{\mathrm{C}=\mathrm{O}}\right) ;{ }^{1} \mathrm{H}$ NMR $\left(\mathrm{CDCl}_{3}\right): \delta 2.2-3.1\left(-\mathrm{CH}_{2}-\mathrm{CH}_{2}-(12 \mathrm{H})\right), 3.5-5.5$ (br, glucose protons, 7H), 6.8-7.4 (aromatic, 15H). 6: IR ( $\mathrm{KBr})$ : $1733\left(\mathrm{v}_{\mathrm{C}=\mathrm{O}}\right)$; ${ }^{1} \mathrm{H}$ NMR $\left(\mathrm{CDCl}_{3}\right)$ : $\delta 0.8-3.3$ (cyclopropane ring $(12 \mathrm{H})$ ), 3.5-5.7 (br, glucose protons, 7H), 6.6-7.4 (aromatic, 15H).

\section{Preparation of chiral stationary phases}

Chiral packing materials were prepared as follows. Macroporous silica gel was treated with an excess amount of 3-aminopropyltriethoxysilane in dry toluene containing a catalytic amount of dry pyridine at $80^{\circ} \mathrm{C}$. After $20 \mathrm{~h}$, the silica gel was successively washed with methanol, acetone and hexane. The amylose esters dissolved in $\mathrm{CHCl}_{3}$ were coated on the aminopropyl silica gel according to the methods used previously for cellulose esters. ${ }^{19,21}$ The solvent was then evaporated under reduced pressure. The weight ratio of the derivatives to silica gel was ca. 20:80. After fractionating the packing materials with sieves, the obtained packing materials were packed into a stainless steel column $(25 \times 0.20 \mathrm{~cm}$ (inner diameter) or $25 \times 0.46 \mathrm{~cm}$ (inner diameter) $)$ using a conventional high-pressure slurry method. The plate number was $700-1500$ for columns with dimensions $25 \times 0.20 \mathrm{~cm}$ (inner diameter) and ca. 3500 for those with dimensions $25 \times 0.46 \mathrm{~cm}$ (inner diameter), for benzene using a hexane-2-propanol $(90 / 10, v / v)$ mixture as the eluent at flow rates of 0.1 and $0.5 \mathrm{ml} \mathrm{min}^{-1}$, respectively. 1,3,5-Tri-tert-butylbenzene was used as a nonretained compound to estimate the dead time $\left(t_{0}\right) .^{24}$

\section{Apparatus}

Chromatographic experiments were performed using a JASCO (Tokyo, Japan) PU-980 chromatograph equipped with ultraviolet (JASCO UV-970) and polarimetric (JASCO OR-990, Hg-Xe without filter) detectors. The column temperature was controlled at $20^{\circ} \mathrm{C}$ using JASCO CO-2060. A solution of the racemate $\left(3 \mathrm{mg} \mathrm{ml}^{-1}\right)$ was injected into the chromatographic system through a Rheodyne Model 7125 injector (Rheodyne, Rohnert Park, CA, USA) with a 
$20 \mu$ loop. ${ }^{1} \mathrm{H}(400 \mathrm{MHz})$ NMR spectra were recorded in $\mathrm{CDCl}_{3}$ and pyridine$d_{5}$ at 55 and $80^{\circ} \mathrm{C}$, respectively, using a Varian Gemini-2000 spectrometer (Varian Gemini, Palo Alto, CA, USA). IR spectra were obtained using a JASCO FT-IR-620 spectrometer as a $\mathrm{KBr}$ pellet. Ultraviolet and circular dichroism spectra were measured in tetrahydrofuran in a $0.1-\mathrm{mm}$ quartz cell using a JASCO Ubset-55 and a JASCO J-720 spectrometer, respectively.

\section{RESULTS AND DISCUSSION}

Enantioseparation on amylose esters

The HPLC resolution on amylose ester-based CSPs was examined for the following 10 racemates: 2-phenylcyclohexanone (8), Tröger base (9), trans-stilbene oxide (10), 1,2,2,2-tetraphenylethanol (11), 2,2'dihydroxy-6,6'-dimethylbiphenyl (12), benzoin (13), flavanone (14), cobalt(III) tris(acetylacetonate) (15), 1-(9-anthryl)-2,2,2-trifluoroethanol (16) and trans-cyclopropanedicarboxylic acid dianilide (17) (Figure 2). Figure 3 shows a chromatogram of the resolution of $\mathbf{1 0}$ on the CSP prepared from amylose cinnamate (3a). The enantiomers eluted at retention times of 17.2 and $26.8 \mathrm{~min}$, showing complete separation. The retention factors, $k_{1}^{\prime}\left[=\left(t_{1}-t_{0}\right) / t_{0}\right]$ and $k_{2}^{\prime}\left[=\left(t_{2}-t_{0}\right) /\right.$ $\left.t_{0}\right]$, were obtained as 1.35 and 2.77 , respectively, and the separation factor $\alpha\left[=k_{2}^{\prime} / k_{1}^{\prime}\right]$ was 2.05 .

The results of the enantioseparation of 10 racemates $(8-17)$ on 4-methylbenzoate 1a, 4-tert-butylbenzoate 1b, 4-phenylbenzoate 1c, $\beta$-naphthoate 2 and cinnamate $3 \mathbf{a}$ of amylose, together with the result on cellulose ester 7 , are summarized in Table $2 .{ }^{25}$ The chiral recognition ability was sensitive to the main-chain structures of polysaccharides. CSP 1a showed almost no chiral recognition ability, in contrast to CSP 7, which had the same side chain as CSP 1a and could separate eight kinds of racemates. This may be because the amylose derivatives probably have a more labile structure than cellulose derivatives. ${ }^{26}$ This indicates that the polymer chain of amylose ester 1a can be influenced by even a small perturbation from outside, making it difficult to have a regular structure, which is important for polymer-based CSPs to show chiral recognition ability. ${ }^{4}$ The CSPs $\mathbf{1 b}, \mathbf{1} \mathbf{c}$ and 2 also showed almost no recognition ability.

On the other hand, amylose cinnamate 3a showed better chiral recognition, and three kinds of racemates in particular, 8, 10 and 17, were efficiently separated by $\alpha$ values $>2$. This result indicates that the bulkiness and stiffness of the cinnamate group of $\mathbf{3 a}$ may be appropriate for 3a to maintain a regular higher-order structure.
Enantioseparation on amylose cinnamate derivatives (3a-3f)

As the cinnamate group was found to be the appropriate side chain for the preparation of amylose ester-based CSPs with a high chiral recognition ability, five new cinnamates (3b-3f in Figure 1) of amylose

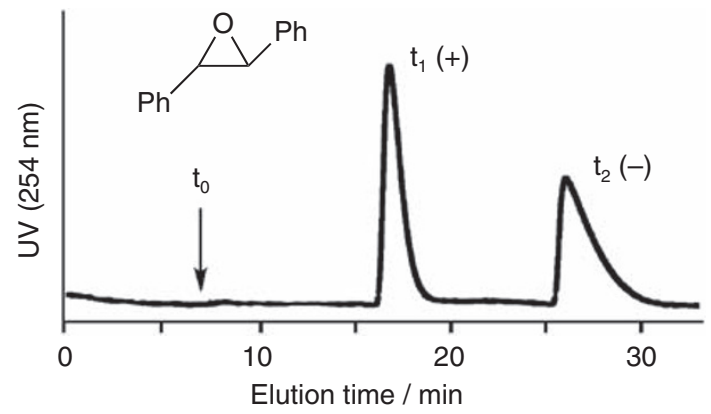

Figure 3 Chiral separation of trans-stilbene oxide $\mathbf{1 0}$ on amylose cinnamate 3a (column: $25 \times 0.20 \mathrm{~cm}$ (inner diameter), eluent: hexane/2-propanol (90:10), flow rate: $0.1 \mathrm{ml} \mathrm{min}^{-1}$ ).

Table 2 Separation factors $(\alpha)$ on ester derivatives of amylose and cellulose $^{a}$

\begin{tabular}{lcccccc} 
Racemates & $1 a\left(4-\mathrm{CH}_{3}\right)$ & $1 b\left(4-\mathrm{C}\left(\mathrm{CH}_{3}\right)_{3}\right)^{b}$ & $1 c(4-P h)$ & $\mathbf{2}$ & $3 a$ & $\boldsymbol{7}$ \\
\hline $\mathbf{8}$ & $\sim 1(-)$ & $\sim 1(-)$ & $\sim 1(-)$ & $\sim 1(-)$ & $2.02(-)$ & $1.32(-)$ \\
$\mathbf{9}$ & $\sim 1(+)$ & 1.0 & $\sim 1(+)$ & 1.0 & 1.0 & $8.43(+)$ \\
10 & $\sim 1(+)$ & $\sim 1(+)$ & $\sim 1(+)$ & 1.0 & $2.05(+)$ & $1.35(+)$ \\
11 & $\sim 1(+)$ & 1.0 & 1.0 & 1.0 & 1.0 & $1.79(+)$ \\
12 & 1.0 & 1.0 & 1.0 & 1.0 & 1.0 & 1.0 \\
13 & 1.0 & $\sim 1(+)$ & 1.0 & 1.0 & $1.14(+)$ & $1.31(-)$ \\
14 & $\sim 1(-)$ & 1.0 & 1.0 & 1.0 & 1.0 & $1.11(-)$ \\
15 & 1.0 & & 1.0 & 1.0 & 1.0 & $\sim 1(+)$ \\
16 & 1.0 & 1.0 & 1.0 & 1.0 & $1.11(+)$ & $1.26(-)$ \\
17 & $\sim 1(+)$ & 1.0 & 1.0 & 1.0 & $3.13(+)$ & $3.90(-)$ \\
\hline
\end{tabular}

aColumn dimensions: $25 \times 0.20 \mathrm{~cm}$ (inner diameter); flow rate: $0.1 \mathrm{ml} \mathrm{min}^{-1}$; eluent: hexane-2propanol $(90: 10)$; temperature: $20^{\circ} \mathrm{C}$. The signs in parentheses represent the optical rotation of the first-eluted enantiomers.

bEluent: hexane.

'The data were reported in Yamamoto et al. ${ }^{25}$<smiles>Cc1ccc2c(c1)CN1CCN2Cc2cc(C)ccc21</smiles>

8<smiles>O=C(c1ccccc1)C(O)c1ccccc1</smiles><smiles>O=C1CC(c2ccccc2)Oc2ccccc21</smiles>

Co(acac)<smiles>Cc1cccc(O)c1-c1c(C)cccc1O</smiles>

11

12

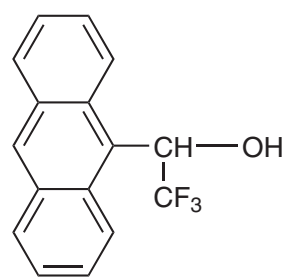

Figure 2 Structures of racemates 8-17. 
Table 3 Separation factors $(\alpha)$ on amylose cinnamate derivatives (3a-3f) ${ }^{a}$

\begin{tabular}{|c|c|c|c|c|c|c|}
\hline Racemates & $3 a$ & $3 b^{\mathrm{b}} \mathrm{CH}_{3}$ & $3 c^{\mathrm{b}} \mathrm{Cl}$ & $3 d$ & $3 e$ & $=$ \\
\hline 8 & $2.02(-)$ & $\sim 1(-)$ & $\sim 1(-)$ & $1.19(-)$ & $1.16(-)$ & $1.60(-)$ \\
\hline 9 & 1.0 & $\sim 1(-)$ & $\sim 1(+)$ & $\sim 1(-)$ & $\sim 1(-)$ & $\sim 1(-)$ \\
\hline 10 & $2.05(+)$ & $1.09(+)$ & $\sim 1(+)$ & $1.36(+)$ & $1.24(+)$ & $1.45(+)$ \\
\hline 13 & $1.14(+)$ & $1.05(+)$ & 1.0 & $1.15(+)$ & $\sim 1(-)$ & $\sim 1(-)$ \\
\hline 14 & 1.0 & $\sim 1(-)$ & 1.0 & $1.06(-)$ & 1.0 & $1.19(+)$ \\
\hline 15 & 1.0 & $\sim 1(-)$ & $\sim 1(-)$ & 1.0 & 1.0 & 1.0 \\
\hline 16 & $1.11(+)$ & 1.0 & 1.0 & 1.0 & 1.0 & 1.0 \\
\hline 17 & $3.13(+)$ & $1.34(+)$ & $1.41(+)$ & $1.66(+)$ & $1.39(+)$ & $2.83(+)$ \\
\hline
\end{tabular}

${ }^{a}$ Column dimensions: $25 \times 0.20 \mathrm{~cm}$ (inner diameter); flow rate: $0.1 \mathrm{ml} \mathrm{min}^{-1}$; eluent: hexane-2-propanol (90:10); temperature: $20^{\circ} \mathrm{C}$. The signs in parentheses represent the optical rotation of the first-eluted enantiomers.

bColumn dimensions: $25 \times 0.46 \mathrm{~cm}$ (inner diameter); flow rate: $0.5 \mathrm{ml} \mathrm{min}^{-1}$.

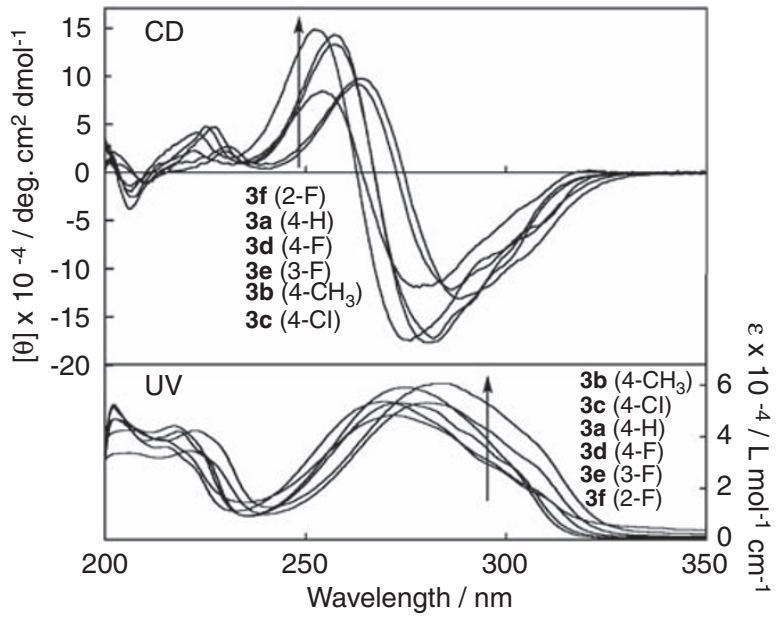

Figure 4 Circular dichroism (upper) and ultraviolet (lower) spectra of amylose cinnamates (3a-3f) in THF at room temperature (cell length: $0.1 \mathrm{~mm}$, concentration: $1.0 \times 10^{-3} \mathrm{M}$ based on glucose units).

were prepared to investigate the influence of substituents on cinnamates in relation to their recognition abilities. The results of the enantioseparation of 10 racemates $(\mathbf{8}-\mathbf{1 7})$ on $\mathbf{3 a}-\mathbf{3 f}$ are summarized in Table 3.

The introduction of any substitution group into the phenyl group caused a negative effect on chiral recognition, and the $\alpha$ values decreased markedly, particularly in CSP 3c, with the chloro group at the para position. Besides $\mathbf{3} \mathbf{a}$, amylose cinnamates $\mathbf{3} \mathbf{b}-\mathbf{3} \mathbf{f}$, having substituents, tended to show recognition ability for racemates $\mathbf{8}, \mathbf{1 0}$, 13 and 17. In addition, racemate 14 was newly resolved on the 4-fluoro- (3d) and 2-fluorocinnamate (3f) derivatives, although the elution orders of enantiomers were reversed on these CSPs.

In the case of cellulose benzoates, electronic properties such as the electron-donating and electron-withdrawing abilities of substituents on the phenyl group affected chiral recognition. ${ }^{21}$ The electrondonating methyl group seemed to slightly improve chiral recognition. This may be ascribed to the increase in electron density on carbonyl oxygen, which can interact with compounds with a hydroxy or carbonyl group through hydrogen bond and dipole-dipole interaction, respectively. However, the separation results on amylose cinnamate derivatives 3 are not explained merely by the electronic effect of the substituents. These results suggest that the phenyl groups of cinnamates are far from the glucose unit because of the existence of a double bond and, therefore, the substituents on the phenyl group cannot significantly influence the polarity of the ester group.

\section{Circular dichroism spectra of amylose cinnamate derivatives (3a-3f)}

The higher-order structure of amylose (3a-3f) derivatives was analyzed using circular dichroism and ultraviolet spectroscopies. As shown in Figure 4, amylose derivatives showed similar split-type circular dichroism spectral patterns in their ultraviolet absorption regions, although the wavelengths and intensities of the peak tops depended on the substituents. This result indicates that amylose cinnamate derivatives 3 may basically possess a similar higher-order structure, which is associated with the similar elution orders of the enantiomers of all racemates except for 14. Two cinnamate groups may exist in positions that are rather close to each other, which leads to the split-type circular dichroism.

\section{Influence of additives}

It is well known that the chiral recognition of cellulose esters is significantly influenced by the preparation conditions of packing materials. ${ }^{19,20,25,27,28}$ Recently, we reported that the recognition ability of cellulose 4-methylbenzoate 7 can be controlled using additives when the derivative is coated on silica gel. ${ }^{25}$ This suggests that the higher-order structure of cellulose esters on silica gel probably varies depending on the coating conditions.

To investigate the effect of additives on the recognition ability of the CSPs derived from amylose esters, several kinds of additives were examined during the preparation of amylose cinnamate-based CSPs. Figure 5 shows the chromatograms of the resolutions of 13 analyzed on CSP 3a that was prepared with and without 2-acetylfuran (18) as an additive during the coating process. When a CSP was prepared from the $\mathrm{CHCl}_{3}$ solution of $3 \mathrm{a}$ without the additive, the (+)-isomer of 13 was first eluted, followed by the $(-)$-isomer, and partial resolution was achieved $(\alpha=1.14)$. On the other hand, on the CSP prepared with 10 equivalents of the additive to a glucose residue, a reversal of the 
a

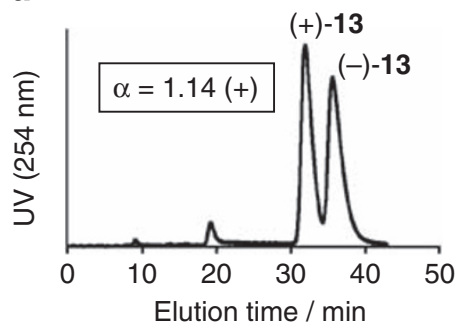

b

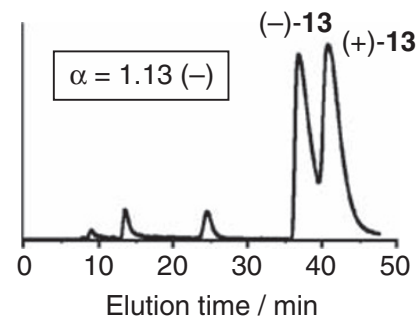<smiles>CC(=O)c1ccco1</smiles>

2-acetylfuran (18)

Figure 5 Chromatograms of the resolutions of benzoin (13) resolved on chiral stationary phases (CSPs) prepared from $\mathbf{3 a}$ in the (a) absence and (b) presence of 2-acetylfuran (18) as additive (column: $25 \times 0.20 \mathrm{~cm}$ (inner diameter), eluent: hexane/2-propanol (90:10), flow rate: $0.1 \mathrm{ml} \mathrm{min}{ }^{-1}$ ).

Table 4 Separation factors $(\alpha)$ on amylose cinnamate derivatives (4) and its analogs (5 and 6)

\begin{tabular}{|c|c|c|c|}
\hline Racemates & 4 & 5 & 6 \\
\hline 8 & $\sim 1(-)$ & $\sim 1(-)$ & $\sim 1(-)$ \\
\hline 9 & 1.0 & 1.0 & 1.0 \\
\hline 10 & $\sim 1(+)$ & $\sim 1(-)$ & 1.0 \\
\hline 11 & 1.0 & $\sim 1(-)$ & 1.0 \\
\hline 12 & 1.0 & 1.0 & 1.0 \\
\hline 13 & 1.0 & $\sim 1(-)$ & $\sim 1(-)$ \\
\hline 14 & $\sim 1(-)$ & 1.0 & 1.0 \\
\hline 15 & 1.0 & 1.0 & 1.0 \\
\hline 16 & 1.0 & 1.0 & 1.0 \\
\hline 17 & 1.0 & 1.0 & $\sim 1(+)$ \\
\hline
\end{tabular}

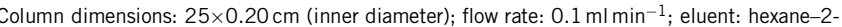
propanol (90:10); temperature: $20^{\circ} \mathrm{C}$. The signs in parentheses represent the optical rotation of the first-eluted enantiomers.

elution order of enantiomers was observed and the (-)-isomer was first eluted with a separation factor of 1.13 . The orientation of the side chains of 3a may be changed through interaction with the additive. When the column was maintained at room temperature for 6 months, recognition ability hardly varied, indicating that the induced structure is rather stably maintained at room temperature. Although the other additives, such as 2-acetyl-5-methylfuran, 2-furancarboxylic acid methyl ester, 2-furancarboxylic acid ethyl ester, 3-acetyl-2,5dimethylfuran, phthalic acid dimethyl ester, $N$-methyl-phthalimide and acetophenone, were used as additives, the reversed elution order was not observed and only a slight change in separation factors was shown between the CSPs prepared in the absence and presence of additives.

Other cinnamate derivative and its analogs

We also prepared the other cinnamate derivative (4) with the methyl group at the $\alpha$-position of the cinnamate, and cinnamate analogs (5 and 6) without the double bond and with a three-membered ring, respectively, and evaluated their chiral recognition ability (Table 4). However, these derivatives showed almost no recognition ability, probably because of lower conformational stability, which causes the formation of many conformational isomers. The results indicate that a precise structural design of ester groups, including bulkiness and stiffness, is necessary to prepare practical CSPs on the basis of amylose esters.

\section{CONCLUSION}

Novel amylose ester derivatives were synthesized and their chiral recognition abilities were evaluated as CSPs for HPLC. Among the derivatives, cinnamate derivatives 3 showed relatively high chiral recognition. The recognition abilities of these derivatives varied significantly depending on the types and positions of substituents of the phenyl groups. In addition, chiral recognition of $\mathbf{3 a}$ was influenced by the preparation conditions of its packing materials, and the CSP 3a prepared with the additive $\mathbf{1 8}$ showed a chiral recognition ability different from that of CSP 3a prepared without the additive.

\section{ACKNOWLEDGEMENTS}

This work was partially supported by Daicel Chemical Industries.

1 Subramanian, G. (ed.). in Chiral Separation Techniques: A Practical Approach 3rd edn (Wiley-VCH, Weinheim, 2007).

2 Okamoto, Y. \& Ikai, T. Chiral HPLC for efficient resolution of enantiomers. Chem. Soc. Rev. 37, 2593-2608 (2008).

3 Ahuja, S. Chiral Separations by Chromatography, (ACS, Washington, DC, 2000).

4 Yamamoto, C. \& Okamoto, Y. Optically active polymers for chiral separation. Bull. Chem. Soc. Jpn. 77, 227-257 (2004).

5 Francotte, E. Enantioselective chromatography as a powerful alternative for the preparation of drug enantiomers. J. Chromatogr. A 906, 379-397 (2001).

6 Taylor, D.R. \& Maher, K. Chiral separations by high-performance liquid-chromatography. J. Chromatogr. Sci. 30, 67-85 (1992).

7 Pirkle, W.H. \& Pochapsky, T.C. Considerations of chiral recognition relevant to the liquid chromatographic separation of enantiomers. Chem. Rev. 89, 347-362 (1989).

8 Armstrong, D.W. Optical isomer separation by liquid chromatography. Anal. Chem. 59, 84A-91A (1987).

9 Okamoto, Y. Separate optical isomers by chiral HPLC. CHEMTECH 17, 176-181 (1987).

10 Yashima, E., Yamamoto, C. \& Okamoto, Y. Polysaccharide-based chiral LC columns. Synlett 344-360 (1998).

11 Okamoto, Y. \& Yashima, E. Polysaccharide derivatives for chromatographic separation of enantiomers. Angew. Chem. Int. Ed. 37, 1020-1043 (1998).

12 Tachibana, T. \& Ohnishi, A. Reversed-phase liquid chromatographic separation of enantiomers on polysaccharide type chiral stationary phases. J. Chromatogr. A 906, 127-154 (2001).

13 Yashima, E. Polysaccharide-based chiral stationary phases for high-performance liquid chromatographic enantioseparation. J. Chromatogr. A 906, 105-125 (2001).

14 Ikai, T., Yamamoto, C., Kamigaito, M. \& Okamoto, Y. Immobilized polysaccharide-based chiral stationary phases for HPLC. Polym. J. 38, 91-108 (2006).

15 Stringham, R.W. The use of polysaccharide phases in the separation of enantiomers. Adv. Chromatogr. 44, 257-290 (2006).

16 Ali, I., Saleem, K., Hussain, I., Gaitonde, V.D. \& Aboul-Enein, H.Y. Polysaccharides chiral stationary phases in liquid chromatography. Sep. Purif. Rev. 38, 97-147 (2009)

17 Hesse, G. \& Hagel, R. Eine vollständige Racemattrennung durch Elutions-Chromatographie an Cellulose-tri-acetat. Chromatographia 6, 277-280 (1973).

18 Hesse, G. \& Hagel, R. Chromatographic resolution of racemates. Liebigs Ann. Chem. 996-1008 (1976) 
19 Okamoto, Y., Kawashima, M., Yamamoto, K. \& Hatada, K. Useful chiral packing materials for high-performance liquid chromatographic resolution. Cellulose triacetate and tribenzoate coated on macroporous silica gel. Chem. Lett. 13, 739-742 (1984).

20 Ichida, A., Shibata, T., Okamoto, I., Yuki, Y., Namikoshi, H. \& Toga, Y. Resolution of enantiomers by HPLC on cellulose derivatives. Chromatographia 19, 280-284 (1984).

21 Okamoto, Y., Aburatani, R. \& Hatada, K. Chromatographic chiral resolution: XIV. Cellulose tribenzoate derivatives as chiral stationary phases for high-performance liquid chromatography. J. Chromatogr. 389, 95-102 (1987).

22 Kubota, T., Yamamoto, C. \& Okamoto, Y. Reversed-phase liquid chromatographic enantioseparation by cycloalkylcarboxylates of cellulose and amylose. Chirality 16, 309-313 (2004).

23 Kaida, Y. \& Okamoto, Y. Optical resolution by supercritical fluid chromatography using polysaccharide derivatives as chiral stationary phases. Bull. Chem. Soc. Jpn. 65, 2286-2288 (1992).
24 Koller, H., Rimböck, K.H. \& Mannschreck, A. High-pressure liquid chromatography on triacetylcellulose: characterization of a sorbent for the separation of enantiomers. J. Chromatogr. 282, 89-94 (1983).

25 Yamamoto, C., Yamada, K., Motoya, K., Kamiya, Y., Kamigaito, M., Okamoto, Y., \& Aratani, T. Preparation of HPLC chiral packing materials using cellulose Tris(4methylbenzoate) for the separation of chrysanthemate isomers. J. Polym. Sci. Part A Polym. Chem. 44, 5087-5097 (2006).

26 Terao, T., Fujii, T., Tsuda, M., Kitamura, S. \& Norisue, T. Solution properties of amylose Tris(phenylcarbamate): local conformation and chain stiffness in 1,4-dioxne and 2-ethoxyethanol. Polym. J. 41, 201-207 (2009).

27 Shibata, T., Okamoto, I. \& Ishii, K. Chromatographic optical resolution on polysaccharides and their derivatives. J. Liq. Chromatogr. 9, 313-340 (1986).

28 Shibata, T., Sei, T. \& Nishimura, H. Hysteretic effect of the coating solvent on chiral recognition by cellulose derivative. Chromatographia 24, 552-554 (1987). 